\title{
Education and communication to increase public understanding of nuclear technology peaceful uses
}

\author{
D. S. Levy, I. P. Santos \\ ${ }^{a}$ Omiccron Programação Gráfica - Rua Maestro Tom Jobim, 133 - 12946-638 Atibaia, SP, Brazil
}

denise@omiccron.com.br

\begin{abstract}
Nuclear technology helps to improve the quality of our everyday life. Nevertheless, there is still great misinformation and the issue divides public opinion. Several surveys were conducted over the past years to study public acceptance of Nuclear Technology in Brazil and worldwide. GlobeScan (2005), for the International Atomic Energy Agency (IAEA), and Eurobarometers (2010), published by the Nuclear Energy Agency (NEA) and the Organization for Economic Co-operation and development (OECD), report similar socio-demographic trends: the higher the education level, the more favorable is public opinion towards nuclear power. Taking into account education and communication are crucial to increase public knowledge and understanding of the benefits of Nuclear Technology and that Internet access has increased strongly all over the country, this educational project aims to take advantage of the potential of Information and Communication Technology (ICT) to disseminate the peaceful use of nuclear technology and its benefits, informing children and teenagers, as well as parents and teachers, who are most often unaware of the matter. Whereas Internet access has increased strongly for both public and private schools all over the country, this web-based educational project, entitled Radioatividades (Radioactivities), provides short courses, curiosities and interactive activities covering topics related to Nuclear Technology and its beneficial applications in several areas, such as medicine, agriculture, industry, art and electric power generation. The project uses the combination of multiple technologies and last generation internet resources. Our target is the dissemination of information, promoting the benefits of Nuclear Technology for new generations, contributing to public acceptance of Nuclear Technology, combating misinformation in our society, omission of the media and knowledge fragmentation. Education transforms old prejudices and inspires new thoughts, stimulating development and encouraging scientific and technological research.
\end{abstract}

Keywords: Information and Communication Technology; public acceptance of nuclear technology; nuclear technology peaceful uses 


\section{INTRODUCTION}

Nuclear technology is part of our everyday life. Over the past decades it has helped to improve the quality of our lifestyle in many more ways than people can realize. Still, there is already great misinformation about the beneficial uses of radiation. The issue divides public opinion in Brazil and worldwide. Most often, the media and social networks associate radiation to nuclear weapons, incidents and accidents. The best known examples throughout history seem to be the big mushroom cloud in Hiroshima and major accidents such as Chernobyl and Fukushima.

Education and communication are crucial to increase public knowledge and understanding of nuclear Technology peaceful applications. Important surveys conducted by GlobeScan (2005) and Eurobarometers (2010) report similar socio-demographic trends: the higher the education level, the more favorable are opinions towards nuclear power.

Eurobarometers are used to measure public opinion in Europe and overseas. Their report, entitled Public Attitudes to Nuclear Power, was published in 2010 by the Nuclear Energy Agency (NEA) and the Organization for Economic Co-operation and Development (OECD). According to this document, "respondents with higher levels of education are more likely to think that the advantages of nuclear outweigh the risks". [01].

The Globescan survey (2005) for the International Atomic Energy Agency (IAEA), published in 2005, analyses the results of public opinion conducted among a thousand adult respondents in each of the eighteen participant countries [02]. According to this report:

"Overall, men (33\%) and people with high levels of education (36\%) are more inclined than women (23\%) and those with low levels of education (24\%) to say that nuclear power is safe and that interested countries should build new nuclear power plants. People with less education (28\%) are more likely than the well educated (21\%) to say that nuclear power is dangerous and that all plants should be closed down."

Nevertheless, a survey conducted by Globescan (2011) for BBC World Service following Fukushima crisis brings different trends: opposition to nuclear energy grows since 2005 [3]. The survey covered 23,231 citizens across 23 countries. In the Latin American countries that do not 
operate nuclear plants, opposition is well-marked. In Chile and Ecuador, respectively, 55\% and $53 \%$ think that nuclear energy is dangerous and should not be used. In Panama and Peru, respectively, 38\% and 30\% think nuclear power generation should be abandoned in countries that have active plants. Brazil was one of the participating countries of this survey, even though only urban samples were used:

"In Brazil - which operates a few nuclear plants and was surveyed for the first time in 2011 - a plurality of 44 per cent of Brazilians says that their country should continue to use the nuclear power stations that are already in operation, but not build new ones. Thirty-five per cent say that nuclear power is dangerous and that all operating nuclear plants should be closed down as soon as possible - above the 12-country average (30\%) - and only 16 per cent support the building of new nuclear plants - below the 12-country average $(22 \%)$."

According to this survey results suggest opposition to nuclear energy grows in many countries and opposition to nuclear power has increased in 5 among 8 countries that were also polled by GlobeScan in 2005. The biggest impact was in Germany where 52\% of the population supported the government's new policy of shutting all the nuclear energy facilities in the country [3].

Some studies conducted in Brazil to measure public acceptance of food irradiation bring similar results, showing that most often the public does not know the difference between food irradiation and radioactive food. Food irradiation is a process that contributes to reduce pathogenic microorganisms and parasites that cause diseases to human health. Besides the health benefits to the consumer, food irradiation could also bring tangible benefits to the national economy: food irradiation helps to delay sprouting and ripening of fresh fruits and vegetables, extending their shelf-life, avoiding losses and waste. However, beyond these benefits there must be considered some intangible aspects: due to lack of knowledge and understanding about the difference between food irradiation and radioactive food, people fear the harmful effects of ionizing radiation to the consumers' health.

Indeed, a study published in Brazil in 2008 [04] clearly demonstrates that misinformation and preconceived ideas impact heavily on the acceptance of irradiated food. This experiment to measure the level of public acceptance considering four different groups: 
- Group 1. Received information and tasted foods identified as irradiated.

- Group 2. Received information and tasted food without knowing whether or not they were irradiated.

- Group 3. Received no information and tasted foods identified as irradiated.

- Group 4. Received no information and tasted food without knowing whether or not they were irradiated.

The third group showed markedly unfavorable results, demonstrating the negative impact of misinformation and prejudice. Another survey entitled "Brazilian Consumer Views on Food Irradiation" was conducted in 2009. The information given to participants about the benefits of irradiated food impacted positively, however participants generally still proved to be fearful about the risks and possible side effects.

The research provided important data about factors which affect acceptance and purchase intention by the Brazilian consumer. In the published conclusions, the authors emphasize the importance of developing an educational program for Brazilian population, explaining the principles, purposes and benefits of food irradiation. [05]

Therefore, this project takes into account two main issues: (i) public opinion is based on experience of the population with the available information about risks and benefits, and (ii) it is not a coincidence that more informed people favor nuclear technology. Any construction depends on a solid foundation and education is the foundation of every society.

Given this challenge, this educational project takes advantage of the potential of new web-based technologies to spread the peaceful uses of nuclear technology and their benefits, informing children and teenagers, as well as their parents and teachers, who are most often unaware of the matter. 


\section{METHODOLOGY}

\subsection{Web-based system development}

The web-based educational Project, entitled RadioAtividades (RadioActivities) aims the dissemination of nuclear technology contents for teachers and students of the Elementary and Secondary Education in schools throughout Brazil [06]. Therefore, we conducted a comprehensive job regarding the possibilities of access to the Information and Communication Technology (ICT) throughout the country. This research work has enabled the collection of quantitative and qualitative data about our target public profile. That allowed us to define the best interfaces tools and resources for this Project.

Internet access has increased strongly all over the country. According to a publication held by the Brazilian Internet Steering Committee [07] who conducted a survey in all Brazilian States, there was an important advance in the use of ICT in Brazilian organizations. This research made use of methodological standards proposed by the United Nations Conference on Trade and Development (UNCTAD), described in the Manual for the Production of Statistics on the Information Economy, produced in partnership with the Organization for Economic Cooperation and Development (OECD), European Commission of Statistics (EUROSTAT) and together with the Measuring ICT for Development, a coalition of various international organizations aiming the harmonization of key indicators on ICT research [07].

In Brazil, between years 2006 to 2008 there was a significant decrease in the use of the dial-up internet from $14 \%$ to only $5 \%$ [08]. Besides, there was significant progress regarding internal wireless network in corporations, which included only $14 \%$ of companies in 2005 . Nevertheless, in $200941 \%$ of Brazilian companies already claimed to have wireless network. These are only few examples that demonstrate the rapid evolution of events and trends of the business market to track the latest technological trends in order to benefit as fully as possible the advances of information technology [07].

The ICT Education 2011 survey [09] comprehended interviews with 1.822 teachers, 606 directors of studies, 640 principals and 6364 students were interviewed between October and December, 2011. 
"The relationship between the frequency of activities carried out in pedagogical practices and the use of ICT suggests a challenge to incorporating technologies in education. There are signs that an increasing number of activities carried out in classrooms will create opportunities for the introduction of ICT in the teacher-student relationship. This is because ICT are used more often to carry out the least frequent activities proposed by teachers. Although there are limitations to the ICT infrastructure of Brazilian schools, the relationship between the most frequent activities and the use of these tools may be indicative that teachers are still struggling to change their teaching practices traditionally carried out without computers or the Internet.

Students in turn, incorporate more naturally the use of computers and the Internet in their school activities. The indicator on activities carried out using ICT shows that $82 \%$ of the students do school research using computers and the Internet. Furthermore, 74\% of them prepare theme projects using ICT, and more than half claim to use these tools for homework assignments (60\%)."

Regarding student access to the internet, this publication report several sample profiles. Age group results show that $40 \%$ of the interviewed students are up to 13 years old and that 14 to 15 year-old students represent $29 \%$ of the sample profile. When each region is studied separately, access to internet are led by Northeast and Southeast regions with a percentage of $34 \%$, and $33 \%$ respectively, while South region represents $16 \%$.The Center-West and North regions have the lowest average rate and together represent $17 \%$ of students access in Brazil. Among the predominantly activities involving the use of computers and the internet for school assignments in public schools, research activities stand in first place, with $82 \%$ of the total number of students in public schools. Overall, there is a higher incidence of computer and Internet use by teachers and students in private schools: "as well as in public teaching institutions, students in the private system also use ICT in their school assignments, particularly for school research $(96 \%)$.

The most recent publication of this entity up to this date [09] shows a comprehensive picture of ICT infrastructure in public and private schools, considering the relationship between the number of students per school and the number of computers in working condition. There are on average 20 operational computers in state or municipal institutions and approximately 500 students per 
school facility, according to the 2011 School Census. Even though $93 \%$ of Brazilian public schools companies claim to have access to Internet, $32 \%$ have connection speeds between 1 and $2 \mathrm{Mbps}$ for the whole facility and a further $25 \%$ have speeds below that. Wireless connections are available in only $45 \%$ of the institutions. Among private schools, there is a higher incidence of computer and Internet, which increases use of ICT with students. Private institutions have on average 29 working computers, nine more than in public institutions, and count on fewer classes per grade and 4 to 5 fewer students per class.

Given these data, we were able to start the system intelligence and the development of educational technology models of nuclear technology content. The pilot project was implemented in a web environment, using the Web 2.0 tools and resources that allow the entire organizational structure. We developed a platform whose range of features and functionality suits the needs of the academic public. Our challenge involved the ability to create an effective, but at the same time flexible system, which please both children and youth.

The project uses the combination of multiple technologies, for both development and infrastructure issues, maximizing the resources available in each technology in order to achieve our goals. Taking into account this is an original project with the prospect of long-term use, it was considered the HTML (XHTML1 STRICT) patterns, according to the W3C (World Wide Web Consortium) recommendations [10]. Considering an infrastructure that supports an average volume of service access, we chose the Linux operating system and MySQL server database [11]. Whether during the implementation phase or hereafter the server has to be rescaled to increased demand, our team can easily migrate the database to a server MSQL Server [12]. For the server language development, we chose PHP [13], as it is a widespread technology, well documented with an extensive and active community, and especially for being a dynamic and flexible language. This WEB 2.0 concept project makes extensive use of CSS (computer language), allowing it to be easily adapted to new possibilities of media, like mobile access, feeds of content and information sharing. There is still a great concern for SEO (computer language) to ensure that the information is well-indexed in the best way possible in the Internet search engines. Furthermore, all content can be accessed from any traditional internet connection, either for computers or mobile technologies. 


\subsection{Delineation of the content}

The website entitled RadioAtividades (RadioActivities) counts on an original and creative design, created according to modern concepts, with different thematic roles which please both children and youth. The header of the website informs visitors about the teaching philosophy of this web-based educational project. [06]

"We do not study the history of navigation from large shipwrecks, we do not learn the history of aviation from the major air accidents. Yet, nuclear technology is often associated with bombs and accidents. Do you know that the peaceful use of nuclear technology contributes strongly to increase our quality of life? Nuclear technology has brought contributions to medicine, industry, agriculture and art!"

The site was developed using modern educational concepts and counts on last generation internet resources which not only replace instructor absence, but also enable students to see and review the content with great quantitative and qualitative achievement. The design includes cards with different themes which can be rated according to the satisfaction degree of the young audience. This project provides different possibilities for activities according to the various contents, such as curiosities, interactive exercises and short courses. Web based short courses, cover topics related to nuclear technology and its beneficial applications in several areas, such as medicine, agriculture, industry and electric power generation.

The content includes concepts, definitions and theory in addition to many interactive activities. The project involves the creation of computerized models that comprise the various aspects of the beneficial applications of nuclear technology: [06]

- Radioactivity - Based on the story of ordinary human beings who, in contact with radiation, became superheroes or super villains, the subject introduces the atom, radioactivity, biological effects of radiation, among other curiosities related to the subject.

- Energy - The topic discusses the various forms of renewable and non-renewable energy, emphasizing the benefits of nuclear energy and explaining the nuclear energy generation and fuel cycle. 
- Transport - This item features transport of dangerous goods, which are essential to improve the quality of our everyday life, such as gasoline, alcohol, varnishes and also radioactive materials. Activities and short courses teach international pictograms used in the transportation of these products and present the specific signals used for Class 7 material.

- Everyday life - The topic discusses how nuclear technology contributes to improve the quality of our everyday life in many more ways than people can realize, such as medicine, agriculture and industry. Two of the short courses present the contributions of nuclear technology in the restoration, maintenance and recognition of works of art and museum collections.

- Nuclear Energy Museum - The topic offers a virtual visit to the Brazilian Nuclear Energy Museum, in Recife (PE), presenting general concepts about several applications of Nuclear Technology, such food irradiation, gemstones irradiation, nuclear power and radiological protection, among others.

- Security and protection - This item offers basic content on radiological protection and security, presenting some actions related to health and safety of the public, the workers and the environment. The topic introduces important concepts and applications, as well as unities and measurements.

This last item is particularly important, for there is still great misunderstanding about the risks involving the harmful effects of ionizing radiations. People fear what they can not understand. Regarding this issue, different areas of this educational site bring different concepts related to safety and security. In addition, there are presented different units for measuring radioactivity exposure, such as absorbed dose, effective dose and equivalent dose, as well as some units like Gray and Sievert. Also, considering workplace safety, children learn about principles of radiation safety to minimize exposure: time, distance and shielding. In addition, the site brings and explains children and teenagers about the three principles of radiological protection, known as optimization, justification and dose limits. This project aims to relate all the content to everyday life. Taking advantage of the FIFA World Cup in Brazil, for example, the site brings information about nuclear and radiological security operations in major public events. 
Moreover, our team provides pedagogical support for teachers, offering supplementary teaching support references material to develop in class. The content bank is designed to clarify and enhance teacher understanding of core in Nuclear Technology issues, providing material resources for free download, such as Power Point presentations and ludic activities. One of the most interesting ways to understand nuclear energy is the possibility to relate it to life itself. Unlike many ideas about nuclear power plants or atomic war, it is more useful and interesting to approach the subject as a natural phenomenon and its relationship to life on Earth.

In this sense, the content bank brings themes such as: "How does life on Earth depend on nuclear energy?" and "Stars: they are the factories of all the things we see on Earth". These themes allow us to explain simple concepts such as the difference between chemical and atomic interactions, nuclear fusion and nuclear fission, the formation of the chemical elements and the concept of radioactive elements. Another example is the Brazilian Multi Proposal Reactor, which has caused reluctance of environmentalists and concerns of the local population. To clarify this issue, the content bank brings information about Nuclear Research Reactors, explains the production of radiopharmaceuticals and emphasizes the importance of nuclear medicine that allows the diagnosis and therapy of various diseases. Furthermore, there was created a restricted access area for teachers, through which our team can collect important reference data about public profile, responding questions such as: who are these teachers, how old are their students, where are they located, how frequently do they visit the website, what kind of material are they interested in and what subjects do they teach. [06]

For now we intend to begin an initial core working general concepts, which in the near future could be extended to more specific contents. As our target is the dissemination of information, all courses are offered to the public at absolutely no cost. In this first phase of the project there are two Brazilian schools using this educational program as an interdisciplinary project, integrating Nuclear Technology Information to other content areas, such as physics, chemistry, biology and art. This investigation of the usage profile will enable important data and suggest new possibilities for the development of the system. 


\section{CONCLUSIONS}

There is still great misinformation about nuclear technology and its beneficial uses of radiation. Public opinion is strongly affected by the media and social networks, which not rarely associate radiation to nuclear weapons or major accidents, like Chernobyl and Fukushima, which had a negative impact on public opinion regarding the use of radiation and its harmful effects on human health. Overall, people seem to be fearful about risks and possible side effects towards activities involving ionizing radiation. Most likely the public opinion would be different if the authorities took more time to invest in individual education of the population, especially in the education of young people.

According to several international entities surveys, more informed people favor nuclear technology. Taking into account that education is the foundation of every society and that Internet access has increased strongly all over the country, this web-based educational project takes advantage of Internet possibilities to disseminate the peaceful use of nuclear technology and its benefits. Our target public is constituted by children and teenagers, as well as their parents and teachers, who are most often unaware of the matter.

Therefore, this educational project intends to present the beneficial uses of radiation in different contexts, such as medicine, agriculture, industry and electric power generation, proving nuclear technology as part of our everyday life and a must to improve the quality of our lifestyle in many more ways than people can realize. The system was created according to a comprehensive study about the realistic scenario of ICT infrastructure in Brazilian schools. Also, taking into account that "despite all investments in introducing ICT in education, there are still great challenges to the effective use of computers and the Internet by teachers in activities with students" [09], in order to improve teaching practices and increase ICT use, teachers are given pedagogical support, which includes a database with teaching support references material with full instructions to develop in class. In this first phase of the project there are two Brazilian schools using this educational program. This experience will enable important data to suggest new possibilities for the development of the system. 
Education transforms old prejudices and inspires new thoughts, stimulating development and encouraging scientific and technological research. Our goal is to promote the benefits of nuclear technology for new generations, combating misinformation in our society, omission of the media and knowledge fragmentation.

\section{ACKNOWLEDGMENTS}

This study benefited greatly from the participation of a number of companies and individuals involved with this educational project. The authors would like to thank all the staff of Omiccron PG and the staff of Inketa Design for their support and assistance. Special thanks to Mr. Alfredo Lopes Ferreira Filho, president of Radiological Protection Brazilian Society, and Dr. Josilto de Aquino, president of Latin American and Caribbean Federation of Radiation Protection Societies, for their appreciation of the benefits to be gained from this independent research. The authors would also like to expressly thank the Nuclear Energy Museum of Federal University of Pernambuco, for the encouragement and kind assistance to this educational initiative.

\section{REFERENCES}

[1] NEA, Nuclear Energy Agency; OECD, Organization for Economic Co-operation and development. Public Attitudes to Nuclear Power. 2010. Available at: <http://www.oecdnea.org/ndd/reports/2010/nea6859-public-attitudes.pdf>. Last accessed: 10 Jun. 2014.

[2] IAEA, International Atomic Energy Agency. Global Public Opinion on Nuclear Issues and the IAEA Final Report from 18 Countries. 2005. Available at: <http://www.iaea.org/Publications/Reports/gponi_report2005.pdf>. Last accessed: 10 Jun. 2014.

[3] BBC World Service, Opposition to Nuclear Energy Grows: Global Poll. 2011. Available at: at: <http://www.globescan.com/images/images/pressreleases/bbc2011_nuclear_energy/ bbc2011_energy.pdf >. Last accessed: 10 Jun. 2014. 
[4] MARTINS C. G. Efeitos da radiação gama na microbiota, no teor de vitamina C de agrião (Nasturtium officinale) orgânico minimamente processado e na aceitação e intenção de compra do produto irradiado. Doctoral Dissertation, Universidade de São Paulo, Brazil, 2008

[5] BEHRENS, J. H.; BARCELLOS, M. N.; FREWER, L. J.; NUNES, T. P.; FRANCO, B. D. G. M.; DESTRO, M. T.; LANDGRAF, M. Brazilian consumer views on food irradiation in Innovative Food Science \& Emerging Technologies, vol 10, pp 383-389. Elsevier, 2009

[6] LEVY, D. S. Portal Educacional RadioAtividades, Available at: <http://www.radioatividades.com.br >. Last accessed: 10 fev. 2015.

[7] CGI, Comitê Gestor da Internet no Brasil. Pesquisa Sobre o Uso das Tecnologias da Informação e da Comunicação no Brasil 2009. Available at: < http://www.cetic.br/tic/2009/index.htm >. Last accessed: 10 Jun. 2014.

[8] CGI, Comitê Gestor da Internet no Brasil. Pesquisa Sobre o Uso das Tecnologias da Informação e da Comunicação no Brasil 2008, Núcleo de Informação e Coordenação do Ponto BR, São Paulo, Brazil, 2009

[9] Brazilian Internet Steering Committee. ICT Education 2011 - Survey on the Use of Information and Communication Technologies in Brazilian Schools. Available at: <http://op.ceptro.br/cgi-bin/cetic/tic-educacao-2011.pdf > . Last accessed: 10 Jun. 2014

[10] World Wide Web Consortium. Available at: <http://www.w3.org/>. Last accessed: 10 Jun. 2014

[11] Improving MySQL Query Analyser - Performance Optimization. Available at: <http://www.mysql.com/>. Last accessed: 10 Jun. 2014

[12] Sqlserver, Net Solutions. Available at: 〈http://www.sqlserver.com/ >. Last accessed: 10 Jun. 2014

[13] Homepage of Php. Available at: < http://www.php.net/>. Last accessed: 10 Jun. 2014 